\title{
Use of AllnN layers in optical monitoring of growth of GaN-based structures on free-standing GaN substrates
}

\author{
I. M. Watson, ${ }^{\text {a) }}$ C. Liu, E. Gu, and M. D. Dawson \\ Institute of Photonics, University of Strathclyde, 106 Rottenrow, Glasgow, G4 ONW, United Kingdom \\ P. R. Edwards and R. W. Martin \\ Department of Physics, University of Strathclyde, 107 Rottenrow, Glasgow, G4 0NG, United Kingdom
}

(Received 10 May 2005; accepted 16 August 2005; published online 3 October 2005)

\begin{abstract}
When lattice matched to GaN, the AlInN ternary alloy has a refractive index $\sim 7 \%$ lower than that of $\mathrm{GaN}$. This characteristic can be exploited to perform in situ reflectometry during epitaxial growth of GaN-based multilayer structures on free-standing GaN substrates, by insertion of a suitable $\mathrm{Al}_{0.82} \mathrm{In}_{0.18} \mathrm{~N}$ layer. The real-time information on growth rates and cumulative layer thicknesses thus obtainable is particularly valuable in the growth of optical resonant cavity structures. We illustrate this capability with reference to the growth of InGaN/GaN multiple quantum-well structures, including a doubly periodic structure with relatively thick $\mathrm{GaN}$ spacer layers between groups of wells. $\mathrm{Al}_{0.82} \mathrm{In}_{0.18} \mathrm{~N}$ insertion layers can also assist in the fabrication of resonant cavity structures in postgrowth processing, for example, acting as sacrificial layers in a lift-off process exploiting etch selectivity between $\mathrm{Al}_{0.82} \mathrm{In}_{0.18} \mathrm{~N}$ and GaN. (C) 2005 American Institute of Physics.
\end{abstract}

[DOI: 10.1063/1.2089175]

The increasing availability of bulk crystal and other forms of free-standing $\mathrm{GaN}(\mathrm{FS}-\mathrm{GaN})$ substrate has been shown to offer improvements in various III-nitride devices, including ultraviolet (UV) light-emitting diodes, ${ }^{1}$ edgeemitting lasers, ${ }^{2}$ and high-frequency transistors. ${ }^{3}$ However, the adoption of GaN as a substrate has hindered the use of optical in situ monitoring techniques during epitaxial growth of device structures. The difficulty lies in the absence of a significant refractive index contrast between the epilayers and the substrate, in contrast to heteroepitaxial growth situations of GaN structures on substrates such as sapphire or silicon carbide. This lack of in situ monitoring capability is a general issue, but is especially problematic for III-nitride photonic devices based on vertical resonant cavities, for which real-time control of layer thicknesses during growth is highly desirable. Examples of these include high-finesse microcavities designed to demonstrate strong light-matter coupling, ${ }^{4,5}$ resonant cavity photodetectors, and various forms of surface-emitting laser (SEL). ${ }^{6}$ The need for precise control of layer thicknesses is reinforced by the frequent requirement to place quantum wells (QWs) at specific depths inside cavities, for example, at electric-field antinode positions in SEL structures designed for resonant periodic gain (RPG). ${ }^{7}$

In this letter, we report a means to apply in situ reflectometry (ISR) to homoepitaxial metalorganic vapor phase epitaxy (MOVPE) of GaN. In the typical heteroepitaxial MOVPE process, the refractive index difference between a GaN film and a sapphire substrate provides a variation in absolute reflectance between $\sim 0.29$ and $\sim 0.08$ as the film thickness satisfies successive constructive and destructive interference conditions. The consequent ease of measuring epilayer growth rates from the period of reflectance oscillations, in close to real time, has made this procedure standard in heteroepitxial MOVPE of III nitrides. ${ }^{8-10}$ Here, we dem-

\footnotetext{
${ }^{a)}$ Electronic mail: i.m.watson@strath.ac.uk
}

onstrate that the insertion of ternary AlInN layers into homoepitaxial GaN-based structures directly facilitates ISR while retaining the advantages of low dislocation density inherent in homoepitaxial growth on GaN substrates. Reports by Carlin and co-workers ${ }^{11-14}$ on distributed Bragg reflectors (DBRs), comprised of alternate layers of AlInN and $\mathrm{GaN}$, previously demonstrated the simultaneous refractive index contrast and in-plane lattice match achievable with this pair of materials. ${ }^{11-14}$ For the lattice-matched composition approximating to $\mathrm{Al}_{0.82} \mathrm{In}_{0.18} \mathrm{~N}$, the refractive index contrast with $\mathrm{GaN}$ at MOVPE growth temperatures was estimated as $7 \%$ at $950 \mathrm{~nm}$. However, all the various structures containing AlInN/GaN DBRs reported by Carlin and co-workers ${ }^{1-14}$ were grown heteroepitaxially on sapphire, in contrast to the homoepitaxial structures discussed here.

Our samples were grown in an Aixtron 200-series MOVPE reactor fitted with a multiwavelength reflectometer. General procedures for optical monitoring and growth of InGaN/GaN structures with this system have been described elsewhere. ${ }^{10}$ The reactor employs gas-foil rotation of substrates at $0.5-3 \mathrm{~Hz}$, and the sampling frequency for reflectance data collection was $\sim 1 \mathrm{~Hz}$. GaN barrier and cap layers of multiple QWs (MQWs) were grown at the same temperature as the InGaN QWs, which were tailored for emission at $\sim 420 \mathrm{~nm}$. ISR data were not subject to any postgrowth corrections, and as-measured reflectances were slightly lower than the expected absolute values, owing to nonparallelism of the substrates. The conditions used for $\mathrm{Al}_{0.82} \mathrm{In}_{0.18} \mathrm{~N}$ growth included a nitrogen ambient, a reactor pressure of 75 millibar, a setpoint temperature of $820^{\circ} \mathrm{C}$, and produced a growth rate of $\sim 130 \mathrm{~nm} \mathrm{~h}^{-1}$. Commercial $10 \mathrm{~mm}$ square wurtzite-phase FS-GaN substrates with (0001) orientation from ATMI Inc. (Danbury, CT) were used. These had threading dislocation densities as low as $3 \times 10^{5} \mathrm{~cm}^{-2}$. Growth of each homoepitaxial structure began with a $1 \mu \mathrm{m} \mathrm{GaN} \mathrm{buffer}$ layer on the FS-GaN substrate, followed by an $\mathrm{Al}_{0.82} \mathrm{In}_{0.18} \mathrm{~N}$ layer $70 \mathrm{~nm}$ in nominal thickness. This physical thickness of $\mathrm{Al}_{0.82} \mathrm{In}_{0.18} \mathrm{~N}$ was intended to give an optical thickness of $\lambda / 4$ 


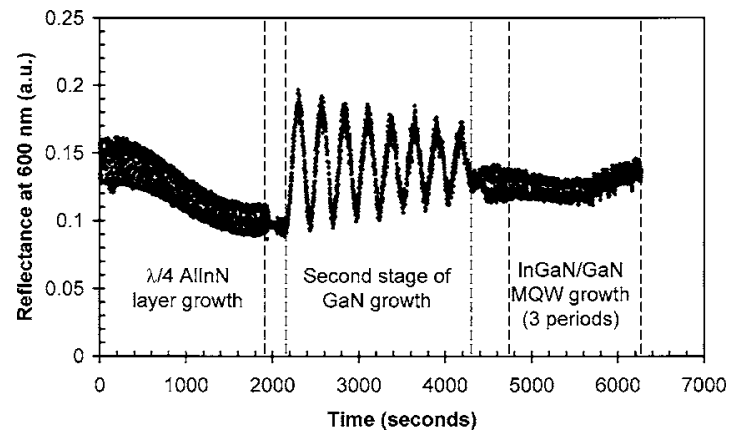

FIG. 1. Reflectance at $600 \mathrm{~nm}$ as a function of time during growth of a structure with three near-surface InGaN QWs, grown on a nominal $1 \mu \mathrm{m}$ GaN layer above a $\lambda / 4 \mathrm{Al}_{0.82} \mathrm{In}_{0.18} \mathrm{~N}$ layer. The dotted vertical lines indicate the start and end of individual growth stages; recipes feature growth pauses to accommodate temperature ramps and switching of gas flows.

at one of our usual monitoring wavelengths, namely $600 \mathrm{~nm}$ (see Fig. 1). The estimate of the index contrast between $\mathrm{GaN}$ and $\mathrm{Al}_{0.82} \mathrm{In}_{0.18} \mathrm{~N}$ from Ref. 11 predicts a corresponding physical thickness of $\sim 68 \mathrm{~nm}$. The InGaN QWs had a nominal thickness of $2.5 \mathrm{~nm}$, and were separated by $7 \mathrm{~nm} \mathrm{GaN}$ barriers. The MQWs were characterized by techniques including atomic force microscopy and cathodoluminescence (CL) hyperspectral imaging, results from which will be reported elsewhere.

The first MQW considered contained a second $1 \mu \mathrm{m}$ GaN layer above the $\mathrm{Al}_{0.82} \mathrm{In}_{0.18} \mathrm{~N}$ layer, and three InGaN QWs grown at $820^{\circ} \mathrm{C}$, covered by a GaN cap of nominal thickness $14 \mathrm{~nm}$. The plot of reflectance versus time in Fig. 1 starts with growth of the $\mathrm{Al}_{0.82} \mathrm{In}_{0.18} \mathrm{~N}$ layer. Because $\mathrm{Al}_{0.82} \mathrm{In}_{0.18} \mathrm{~N}$ has a lower refractive index than GaN, the reflectance decreased as this layer grew, and the target optical thickness of $\lambda / 4$ resulted in the growth step ending at a reflectance minimum. The calculated change in absolute reflectance during growth of a $\lambda / 4$ layer of $\mathrm{Al}_{0.82} \mathrm{In}_{0.18} \mathrm{~N}$ on FS-GaN is 0.175 to 0.131 . The experimental reflectance data corresponding to $\mathrm{Al}_{0.82} \mathrm{In}_{0.18} \mathrm{~N}$ growth show a significant noise envelope, caused by the combination of the substrate rotation and its nonideal parallelism. The relatively slow growth rates during $\mathrm{Al}_{0.82} \mathrm{In}_{0.18} \mathrm{~N}$ and $\mathrm{MQW}$ growth tend to emphasize fluctuations in measured reflectance, and we find that the different rotation speeds under different growth conditions also affect the signal stability. However, it is clear that ISR could be used for accurate control of the $\mathrm{Al}_{0.82} \mathrm{In}_{0.18} \mathrm{~N}$ layer thickness if required, for example stopping growth at a reflectance extremum. Neglecting absorption effects, $\mathrm{Al}_{0.82} \mathrm{In}_{0.18} \mathrm{~N}$ layers of any optical thickness $m \lambda / 4$, where $m$ is an odd integer, would give similar reflectance wave forms during the growth of the remainder of the structure. However, the lowest thickness with $m=1$ minimizes the risk of misfit dislocations forming if the compositional control, and hence lattice matching to $\mathrm{GaN}$, is imperfect. During growth of the GaN layer above the $\mathrm{Al}_{0.82} \mathrm{In}_{0.18} \mathrm{~N}$ layer, large-amplitude reflectance oscillations were observed, and the GaN growth rate was measured to be $1.65 \mu \mathrm{m} \mathrm{h}^{-1}$, assuming a high-temperature refractive index of $2.44 .^{15^{3}}$ Growth of the three QW stack completing this structure corresponded to only a small fraction of an optical cycle.

As a second example, we discuss a more complex structure containing 15 QWs arranged in an RPG configuration. This was designed to function as an external cavity SEL, after integration of the active region with an oxide-based

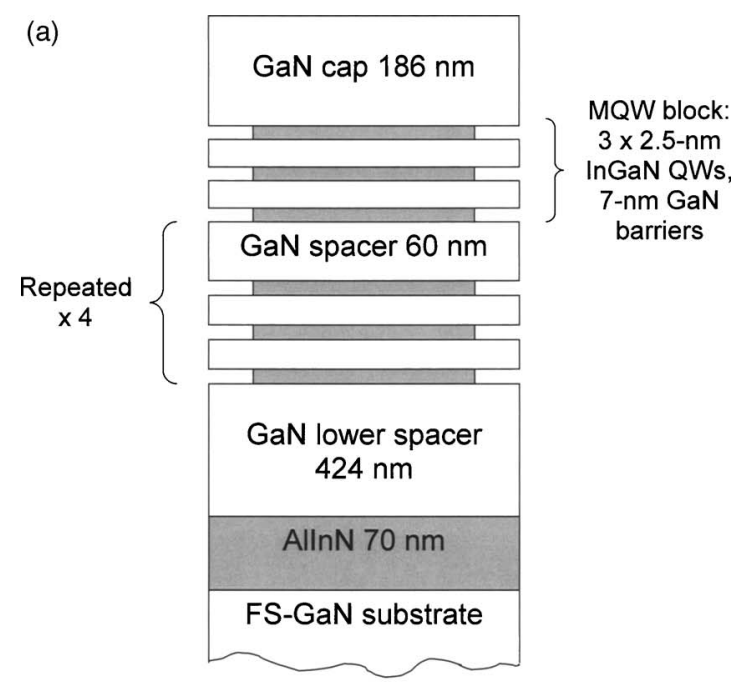

(b)

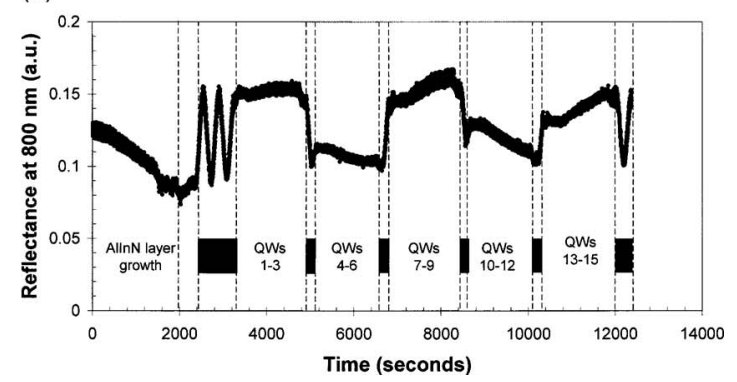

FIG. 2. (a) Schematic cross section through the RPG-MQW, containing 15 QWs positioned in five groups of three. (b) Reflectance at $800 \mathrm{~nm}$ vs time during growth. Marker bars between dotted vertical lines indicate the hightemperature $\mathrm{GaN}$ growth steps used for an initial $\mathrm{GaN}$ layer above the $\mathrm{Al}_{0.82} \mathrm{In}_{0.18} \mathrm{~N}$ layer, GaN spacers between groups of QWs, and a final cap layer.

DBR. Information on the structure and target layer thicknesses is presented in Fig. 2(a), while Fig. 2(b) shows the time dependence of the sample reflectance during growth. Growth of such RPG-MQWs in the InGaN/GaN system requires repeated temperature cycling between the high growth temperature (here $1130{ }^{\circ} \mathrm{C}$ ) necessary to grow $\mathrm{GaN}$ spacer layers in a practical time, and the lower temperature (here $835^{\circ} \mathrm{C}$ ) obligatory for InGaN growth. Including $3.5 \mathrm{~nm}$ lowtemperature $\mathrm{GaN}$ protective layers grown above the final QW in each three-well group, only $13 \%$ of the total thickness of the structure was grown under the lower-temperature conditions. Therefore, real-time measurement of the hightemperature $\mathrm{GaN}$ growth rate applicable to the spacer layers was essential for accurate control of the total cavity thickness, and QW positions. A growth rate of $1.69 \mu \mathrm{m} \mathrm{h}^{-1}$ was measured for the first GaN layer above the $\mathrm{Al}_{0.82} \mathrm{In}_{0.18} \mathrm{~N}$ layer, allowing appropriate adjustment of the periods for the subsequent GaN spacer layers. Iterative simulation of a reflectance spectrum measured ex situ indicated a total thickness of $923 \mathrm{~nm}$ for the $\mathrm{GaN}$ and InGaN layers above the $\mathrm{Al}_{0.82} \mathrm{In}_{0.18} \mathrm{~N}$ layer, compared to a target value of $958 \mathrm{~nm}$. Thermal expansion of GaN along [0001], which was not allowed for in our thickness calibration procedure, will contribute approximately one-half of this difference between the target and actual structure thickness. ${ }^{16}$ Investigations of the effects of $\mathrm{Al}_{0.82} \mathrm{In}_{0.18} \mathrm{~N}$ layers on the properties of QWs are ongoing, but we note that the 15 QW sample discussed showed a four-fold increase in integrated CL peak intensity license or copyright; see http://apl.aip.org/about/rights_and_permissions 

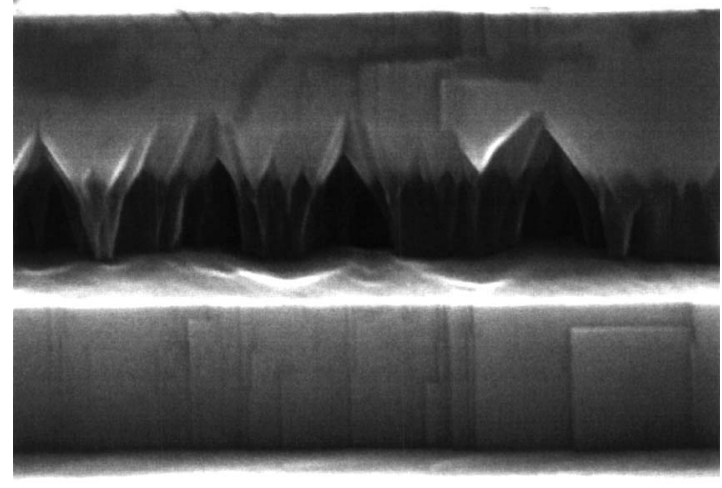

$200 \mathrm{~nm}$

FIG. 3. Secondary electron image of the edge of a mesa in a $\mathrm{GaN} / \mathrm{Al}_{0.82} \mathrm{In}_{0.18} \mathrm{~N} / \mathrm{GaN}$ trilayer structure on sapphire, after etching in alkaline solution. The nominal thickness of the top GaN layer is $500 \mathrm{~nm}$, and that of the $\mathrm{Al}_{0.82} \mathrm{In}_{0.18} \mathrm{~N}$ layer $300 \mathrm{~nm}$. The mesa etch stopped within the lower $1 \mu \mathrm{m} \mathrm{GaN}$ layer, so that the horizontal surface visible at the bottom of the image is $\mathrm{GaN}$.

compared to an analogous structure grown on sapphire without any $\mathrm{Al}_{0.82} \mathrm{In}_{0.18} \mathrm{~N}$ layer.

An additional role for AlInN insertion layers in fabrication of homoepitaxial III-nitride microcavity structures is suggested by the differences in etching characteristics between AlInN and GaN. In initial experiments, we have demonstrated that lattice-matched $\mathrm{Al}_{0.82} \mathrm{In}_{0.18} \mathrm{~N}$ wet etches much faster than $\mathrm{GaN}$ in various alkaline media. Figure 3 shows a secondary electron image of the edge of a mesa, initially defined by inductively coupled plasma etching, in a threelayer $\mathrm{GaN} / \mathrm{Al}_{0.82} \mathrm{In}_{0.18} \mathrm{~N} / \mathrm{GaN}$ structure grown on sapphire (0001). The mesa-etched sample was held in $\sim 6 \%$ aqueous potassium hydroxide solution for $24 \mathrm{~h}$ at room temperature, and this treatment caused preferential undercutting of the $\mathrm{Al}_{0.82} \mathrm{In}_{0.18} \mathrm{~N}$ layer. The conical morphology of the remaining $\mathrm{Al}_{0.82} \mathrm{In}_{0.18} \mathrm{~N}$, which shows dark contrast in the figure, resembles that reported by Stonas et al. ${ }^{17}$ for the early stages of a more complex photoelectrochemical lift-off process, using a buried InGaN layer. Device fabrication routes involving dissolution of sacrificial $\mathrm{Al}_{0.82} \mathrm{In}_{0.18} \mathrm{~N}$ would avoid issues of lattice mismatch inherent in the use of $\mathrm{InGaN}$ layers. $\mathrm{Al}_{0.82} \mathrm{In}_{0.18} \mathrm{~N}$ insertion layers could also facilitate etch depth calibration during dry etching, for example, acting as marker layers in processes using appropriate diagnostics to detect the appearance of aluminum and/or indium species in the plasma.

In summary, insertion of a $\lambda / 4 \mathrm{Al}_{0.82} \mathrm{In}_{0.18} \mathrm{~N}$ layer into III-nitride multilayer structures grown on FS-GaN substrates allows oscillations of useful amplitude to be obtained in in situ reflectance traces, without the introduction of lattice mismatch. The $\mathrm{Al}_{0.82} \mathrm{In}_{0.18} \mathrm{~N}$ layer thus facilitates real-time mea- surement of growth rates by a standard method, and allows accurate control of layer thicknesses, which is of special importance for homoepitaxial resonant cavity structures. As an illustration, we have discussed an $\mathrm{InGaN} / \mathrm{GaN} \mathrm{MQW}$ structure containing 15 QWs in an RPG configuration, and incorporating a relatively thick $(\sim 420 \mathrm{~nm}) \mathrm{GaN}$ layer immediately above the $\mathrm{Al}_{0.82} \mathrm{In}_{0.18} \mathrm{~N}$. This structure design allowed an intrarun calibration of the high-temperature $\mathrm{GaN}$ growth rate, which was used to control thicknesses of subsequent thinner $(60 \mathrm{~nm}) \mathrm{GaN}$ spacer layers. $\mathrm{Al}_{0.82} \mathrm{In}_{0.18} \mathrm{~N}$ insertion layers also offer promise as sacrifical layers in fabrication sequences using alkaline wet etches, and as etch stop or marker layers in dry etch processes.

The authors acknowledge funding from the Clermont 2 European Union network (MRTN-CT-2003-503577) and BTG plc, and thank S. Calvez for his inputs on structure design.

${ }^{1}$ X. A. Cao, S. F. LeBoeuf, M. P. D’Evelyn, S. D. Arthur, J. Kretchmer, C. H. Yan, and Z. H. Yang, Appl. Phys. Lett. 84, 4314 (2004).

${ }^{2}$ C. Skierbiszewski, Z. R. Wasilewski, M. Siekacz, A. Fedniewicz, P. Perlin, P. Wisniewski, J. Borysiuk, I. Grzegory, M. Leszcynski, T. Suski, and S. Porowski, Appl. Phys. Lett. 86, 011114 (2005).

${ }^{3}$ K. K. Chu, P. C. Chao, M. T. Pizella, R. Actis, D. E. Meharry, K. B. Nichols, R. P. Vaudo, X. Xu, J. S. Flynn, J. Dion, and G. R. Brandes, IEEE Electron Device Lett. 25, 596 (2004).

${ }^{4}$ T. Tawara, H. Gotoh, T. Akaska, N. Kobayashi, and T. Saitoh, Phys. Rev. Lett. 92, 256402 (2004).

${ }^{5}$ N. Antoine-Vincent, F. Natali, D. Byrne, A. Vasson, P. Disseix, J. Leymarie, M. Leroux, F. Semond, and J. Massies, Phys. Rev. B 68, 153313 (2003).

${ }^{6}$ T. Someya, R. Werner, A. Forchel, M. Catalano, R. Cingolani, and Y. Arakawa, Science 285, 1905 (1999).

${ }^{7}$ M. Y. A. Raja, S. R. J. Bruek, M. Osinski, C. F. Schaus, J. G. McInerney, T. M. Brennan, and B. E. Hammons, IEEE J. Quantum Electron. 25, 1500 (1989).

${ }^{8}$ R. S. Balmer, C. Pickering, A. J. Pidduck, and T. Martin, J. Cryst. Growth 245, 198 (2002).

${ }^{9}$ H. Hardtdegen, N. Kaluza, R. Schmidt, R. Steins, E. V. Yakovlev, R. A. Talalaev, Y. N. Makarov, and J.-T. Zettler, Phys. Status Solidi A 201, 312 (2004).

${ }^{10}$ C. J. Deatcher, C. Liu, S. Pereira, M. Lada, A. G. Cullis, Y. J. Sun, O. Brandt, and I. M. Watson, Semicond. Sci. Technol. 18, 212 (2003).

${ }^{11}$ J.-F. Carlin and M. Ilegems, Appl. Phys. Lett. 83, 668 (2003).

${ }^{12}$ J. Dorsaz, J.-F. Carlin, C. M. Zellweger, S. Gradecak, and M. Ilegems, Phys. Status Solidi A 201, 2675 (2004).

${ }^{13}$ J.-F. Carlin, J. Dorsaz, E. Feltin, R. Butté, N. Grandjean, M. Ilegems, and M. Läugt, Appl. Phys. Lett. 86, 031107 (2005).

${ }^{14}$ E. Feltin, R. Butté, J.-F. Carlin, J. Dorsaz, N. Grandjean, and M. Ilegems, Electron. Lett. 41, 94 (2005).

${ }^{15}$ S. Peters, T. Schmidtling, T. Trepk, U. W. Pohl, J.-T. Zettler, and W. Richter, J. Appl. Phys. 88, 4085 (2000).

${ }^{16}$ M. Leszcyczynski, T. Suski, H. Teisseyre, P. Perlin, I. Grzegory, J. Jun, S. Porowski, and T. D. Moustakas, J. Appl. Phys. 76, 4909 (1994).

${ }^{17}$ A. R. Stonas, T. Margalith, S. P. Denbaars, L. A. Coldren, and E. L. Hu, Appl. Phys. Lett. 78, 1945 (2001). 